\title{
Sequela-free long-term survival of a 65-year-old woman after 8 hours and 40 minutes of cardiac arrest from deep accidental hypothermia
}

\author{
Marie Meyer, MD, ${ }^{\mathrm{a}}$ Nathalie Pelurson, $\mathrm{MD},{ }^{\mathrm{b}}$ Ebrahim Khabiri, $\mathrm{MD},{ }^{\mathrm{c}}$ Nils Siegenthaler, $\mathrm{MD},{ }^{\mathrm{d}}$ and \\ Beat H. Walpoth, MD, ${ }^{\mathrm{c}}$ Geneva, Switzerland, and Embrun, France
}

In the setting of accidental deep hypothermia, rare cases of lengthy cardiac arrests may be associated with excellent long-term cardiovascular and neurologic outcomes. These unusual cases should be reported to a registry and studied further to advance our knowledge and improve treatments and outcomes for those affected by accidental deep hypothermia. We present here the longest, to our knowledge, cardiac arrest with an excellent long-term outcome.

\section{CLINICAL SUMMARY}

At around midnight, the 65-year-old patient had been declared missing. Medical history consisted of chronic depression treated by sertraline hydrochloride (INN sertraline) in the context of a difficult family situation. At 7:00 AM, hunters unexpectedly found the woman gasping on a snow-covered riverbank. At 7:15 AM, the firefighters arrived, diagnosed cardiac arrest, and started cardiopulmonary resuscitation (CPR). At 7:30 AM, the medical rescue team arrived, confirming deep hypothermia at $28^{\circ} \mathrm{C}$ rectal

\footnotetext{
From the Service of Anesthesiology, ${ }^{\text {a }}$ University Hospital of Geneva, Geneva, Switzerland; the Emergency Department, ${ }^{b}$ Centre Hospitalier d'Embrun, Embrun, France; the Service of Cardiovascular Surgery, ${ }^{\mathrm{c}}$ University Hospital of Geneva, Geneva, Switzerland; and the Service of Intensive Care, ${ }^{\mathrm{d}}$ University Hospital of Geneva, Geneva, Switzerland.

Disclosures: Authors have nothing to disclose with regard to commercial support.

Received for publication May 14, 2013; revisions received Aug 1, 2013; accepted for publication Aug 16, 2013; available ahead of print Oct 30, 2013.

Address for reprints: Marie Meyer, MD, Service of Anesthesiology, University

Hospital of Geneva, Rue Gabrielle-Perret-Gentil 4, 1205 Geneva, Switzerland

(E-mail: marie.meyer@hcuge.ch).

J Thorac Cardiovasc Surg 2014;147:e1-2

$0022-5223 / \$ 36.00$

Copyright (c) 2014 by The American Association for Thoracic Surgery

http://dx.doi.org/10.1016/j.jtcvs.2013.08.085
}

temperature and cardiac arrest on asystole. No external traumatic lesions were noticed, nor were there suspicions of asphyxia. The patient was intubated and received a total of $8 \mathrm{mg}$ of epinephrine through the intravenous and tracheal routes, without response. She was conveyed by ambulance to the University Hospital of Geneva under continuous manual CPR (Figure 1). Despite thermal isolation and removal of wet clothing, the patient's core temperature dropped to a minimum of $20.8^{\circ} \mathrm{C}$ as rectally measured at initiation of cardiopulmonary bypass (CPB) rewarming. In the emergency department, serum and blood gas samples (not corrected for temperature, according to the alpha-stat theory) showed moderately compensated mixed acidosis with a $\mathrm{pH}$ of 6.94 , hyperglycemia, and moderate hypokalemia of $2.8 \mathrm{mmol} / \mathrm{L}$ (Table 1). The search for toxic substances in the blood suggested the presence of an associated selective serotonin reuptake inhibitor intoxication. CPB rewarming was started at 12:03 PM by femorofemoral cannulation with a heparinized circuit after 288 minutes of continuous CPR on asystole. The rewarming rate chosen was slow, at $4^{\circ} \mathrm{C} / \mathrm{h}$. External rewarming by a forced air blanket was added in parallel. During rewarming, the patient's cardiac rhythm changed on reaching $22^{\circ} \mathrm{C}$ from asystole to ventricular fibrillation, which persisted until defibrillation. At $31^{\circ} \mathrm{C}$, a unique 120-J external shock restored sinus rhythm. With low doses of norepinephrine, the patient was weaned from $\mathrm{CPB}$ at $36^{\circ} \mathrm{C}$, after 232 minutes of active rewarming, and sent to intensive care. Complications after rewarming consisted of rhabdomyolysis (maximum total creatine kinase 24,000 U/L) without secondary complications, left ventricular dysfunction with $45 \%$ ejection fraction, hemodynamic instability requiring

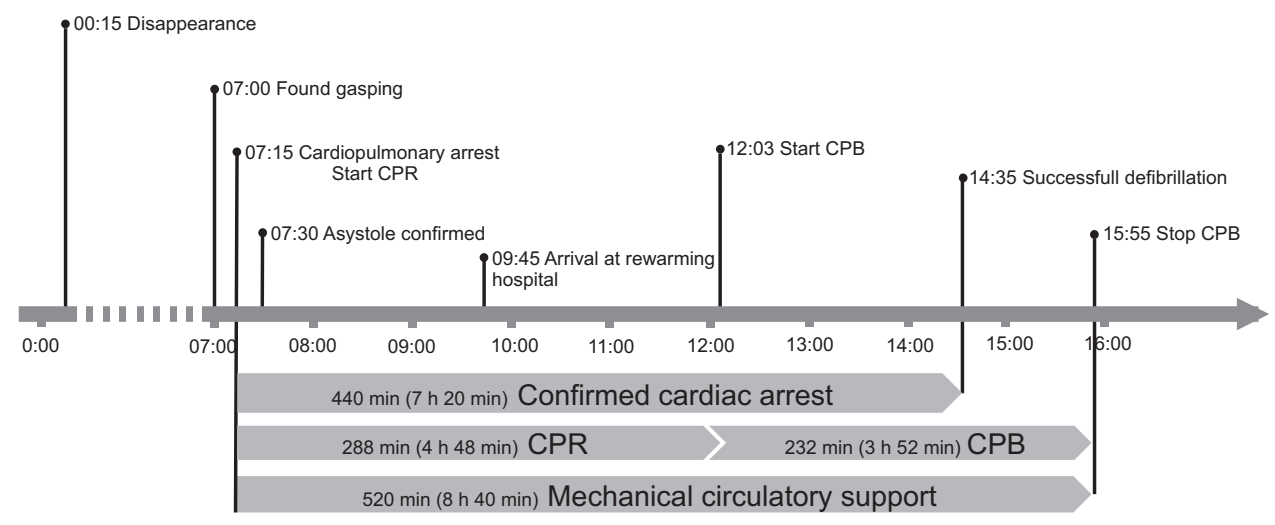

FIGURE 1. Resuscitation time line. $C P R$, Cardiopulmonary resuscitation; $C P B$, cardiopulmonary bypass. 
TABLE 1. Prerewarming and postrewarming patient blood gas analysis values

\begin{tabular}{lcccccccc}
\hline & $\mathbf{p H}$ & $\mathbf{P a C O}_{\mathbf{2}}(\mathbf{k P a})$ & $\mathbf{P a O}_{\mathbf{2}}(\mathbf{k P a})$ & $\mathbf{H C O}_{\mathbf{3}}{ }^{-}(\mathbf{m m o l} / \mathbf{L})$ & $\mathbf{B E}(\mathbf{m m o l} / \mathbf{L})$ & Lactate $_{(\mathbf{m m o l} / \mathbf{L})}$ & $\mathbf{A C T}(\mathbf{s})$ & $\mathbf{K}^{+}(\mathbf{m m o l} / \mathbf{L})$ \\
\hline Prerewarming & 6.94 & 6.30 & 65.5 & 9.7 & -20.6 & 6.7 & $>999$ & 2.8 \\
Postrewarming & 7.10 & 7.21 & 15.7 & 16.1 & -13 & 3.4 & 223 \\
\hline
\end{tabular}

The arterial values are not corrected for temperature, according to the alpha-stat theory. $\mathrm{HCO}_{3}{ }^{-}$, Bicarbonate ion; $\mathrm{BE}$, base excess; $\mathrm{ACT}$, activated clotting time; $\mathrm{K}^{+}$, potassium ion; $\mathrm{PaCO}_{2}$, arterial partial pressure of carbon dioxide; $\mathrm{PaO}_{2}$, arterial partial pressure of oxygen.

norepinephrine until day 3 , and acute pulmonary edema that required mechanical ventilatory support until day 5 , with an autoextubation on day 4 (reintubation was not necessary). Agitation and delirium were controlled with haloperidol started on day 4 after weaning from sedation with propofol. She was dismissed from the intensive care unit on day 5 and was hospitalized 4 weeks before undergoing cardiac and neuropsychologic rehabilitation for another 4 weeks. At the end of rehabilitation, neurologic impairments consisted of moderate semantic memory deficits and fine finger movement disorders requiring further ambulatory followups. Five years later, in October 2012, the patient underwent physical, neurologic, and psychologic examinations, as well as a echocardiography and electrocardiography, to assess any remaining long-term cardiac or neurologic impairments. The cardiac examinations demonstrated complete recovery of the left ventricular dysfunction, with an ejection fraction of $65 \%$. No other structural or functional anomalies were reported. The electrocardiogram was normal, and all neurologic impairments had resolved except for minimal semantic memory deficits, which did not affect the patient's daily life.

\section{DISCUSSION}

Our patient survived 288 minutes (4 hours and 48 minutes) of cardiac arrest under external manual cardiac massage and a total of 520 minutes ( 8 hours and 40 minutes) of mechanical circulatory support (CPR and CPB) before she could sustain her own circulation and be weaned from $\mathrm{CPB}$. According to our literature review, this is the longest cardiac arrest with an excellent long-term outcome. The longest cardiac arrests so far in a hypothermic setting have been reported as 190 minutes of continuous CPR before initiation of $\mathrm{CPB},{ }^{1} 390$ minutes of $\mathrm{CPR}$ before restoration of cardiac function under peritoneal lavage and forced air blankets, ${ }^{2}$ and 412 minutes of total resuscitation time (CPR plus CPB). ${ }^{3}$ As in our case, a decrease in myocardial function may result from hypothermia and rewarming. Myocardial function seems to decrease during deep hypothermia $\left(<30^{\circ} \mathrm{C}\right)$, in contrast to mild hypothermia (increased contractility), to progress with the duration of hypothermia and prevail after rewarming. The pathophysiology of hypothermia-induced cardiac failure is not completely understood, it seems to involve, as in myocardial stunning, a dysfunction of ion transport leading to intracellular calcium overload. ${ }^{4}$ In this case, the decrease in heart function was moderate and recovered completely. Extracorporeal membrane oxygenation seems to be the rewarming method of choice in cases of deep hypothermia with cardiac arrest and is associated with the best outcomes today. ${ }^{5}$ Because extracorporeal membrane oxygenation was not in the treatment protocols of the hospital at that time, classic CPB was chosen. In the effort to advance in knowledge, treatments, and outcomes of accidental deep hypothermia, there is a need to enter these rare cases in the newly operational International Hypothermia Registry. ${ }^{6}$ In conclusion, this case of the longest documented hypothermic cardiac arrest demonstrates that patients with extremely long cardiac arrests can survive with excellent cardiovascular and neurologic long-term outcomes.

\section{References}

1. Husby P, Andersen KS, Owen-Falkenberg A, Steien E, Solheim J. Accidental hypothermia with cardiac arrest: complete recovery after prolonged resuscitation and rewarming by extracorporeal circulation. Intensive Care Med. 1990;16: 69-72.

2. Lexow K. Severe accidental hypothermia: survival after 6 hours 30 minutes of cardiopulmonary resuscitation. Arctic Med Res. 1991;50(Suppl 6):112-4.

3. Mark E, Jacobsen O, Kjerstad A, Naesheim T, Busund R, Bahar R, et al. Hypothermic cardiac arrest far away from the center providing rewarming with extracorporeal circulation. Int J Emerg Med. 2012;5:7.

4. Kondratiev TV, Wold RM, Aasum E, Tveita T. Myocardial mechanical dysfunction and calcium overload following rewarming from experimental hypothermia in vivo. Cryobiology. 2008;56:15-21.

5. Ruttmann E, Weissenbacher A, Ulmer H, Müller L, Höfer D, Kilo J, et al. Prolonged extracorporeal membrane oxygenation-assisted support provides improved survival in hypothermic patients with cardiocirculatory arrest. $J$ Thorac Cardiovasc Surg. 2007;134:594-600.

6. International Hypothermia Registry. IHR project. Available at: https://www. hypothermia-registry.org/. Accessed January 3, 2013. 